\title{
PENINGKATAN LOYALITAS MUZAKKI DALAM MEMBAYAR ZAKAT MELALUI SERVICE EXCELLENCE
}

\section{INCREASING MUZAKKI'S LOYALITY IN PAYING ZAKAT THROUGHT SERVICE EXCELLENCE}

\author{
Yusuf, La Ode Anto \\ Fakultas Ekonomi dan Bisnis Universitas Halu Oleo \\ JL. H.E.A Mokodompit. Kampus Bumi Tridharma Anduonohu, Kendari \\ yusufrauf@uho.ac.id, laodeanto@gmail.com \\ Nofrivul, Ulya Atsani \\ Fakultas Ekonomi dan Bisnis Islam IAIN Batusangkar \\ Kampus II IAIN Batusangkar Jl. Raya Batusangkar-Padang Panjang KM.7 \\ nofrivul@iainbatusangkar.ac.id, ulyaatsani@iainbatusangkar.ac.id
}

Naskah diterima 20 Juli 2020, di-review 07 September 2020, disetujui 31 Desember 2020

\begin{abstract}
This study aims to analyze the effect of service excellence on increasing Muzakki's loyalty in paying zakat at Baznas of Southeast Sulawesi Province. This research was conducted on the people of Southeast Sulawesi province who paid zakat at the Southeast Sulawesi Provincial Baznas of 120 people. Analysis of the data used in this study is multiple linear regression. The results of this study indicate that service excellence consisting of attitude, attention, action, ability, appereance, and accountability significantly plays a role in increasing Muzakki's loyalty
\end{abstract}

Keywords: Loyality, Muzakki, Zakat \& Service Excellence

\begin{abstract}
Abstrak: Penelitian ini bertujuan untuk menganalisis pengaruh service excellence terhadap peningkatan loyalitas Muzakki dalam membayar zakat pada Baznas Provinsi Sulawesi Tenggara. Penelitian ini dilakukan pada masyarakat provinsi Sulawesi Tenggara yang membayarkan zakatnya pada Baznas Provinsi Sulawesi Tenggara sebanyak 120 orang. Analisis data yang digunakan dalam penelitian ini adalah regresi linier berganda. Hasil penelitian ini menunjukkan bahwa service excellence yang terdiri attitude, attention, action, ability, appereance, dan accountability secara signifikan berperan dalam peningkatan loyalitas Muzakki
\end{abstract}

Kata Kunci: Loyalitas, Muzakki, Zakat \& Service Excellence

\section{PENDAHULUAN}

$\mathcal{L}_{1999 \text { tentang Pengelolaan Zakat merupakan }}^{\text {ahirnya Undang-Undang Nomor } 38 \text { Tahun }}$ langkah awal pengelolaan zakat yang berlaku secara Nasional. Berdasarkan Surat Keputusan disebutkan tugas dan fungsi BAZNAS (Badan Amil Zakat Nasional) yaitu untuk melakukan penghimpunan dan pendayagunaan zakat. Undang-Undang tersebut menjelaskan bahwa ada dua jenis organisasi pengelola zakat yaitu Badan Amil Zakat (BAZ) yang dibentuk pemerintah dan Lembaga Amil Zakat (LAZ) yang dibentuk oleh masyarakat dan dikukuhkan oleh pemerintah. Adapun BAZ terdiri dari BAZNAS pusat, BAZ Propinsi, BAZ kota, BAZ Kecamatan. 
Terbentuknya lembaga zakat yang berbadan hukum dan didukung dengan sosialisasi zakat yang dilakukan oleh lembaga zakat di berbagai media berdampak pada peningkatan kesadaran masyarakat untuk berzakat melalui amil zakat. Sejak tahun 2002 total dana zakat yang berhasil dihimpun BAZNAS dan LAZ mengalami peningkatan pada tiap tahunnya. Selain itu, pendayagunaan zakat juga semakin bertambah luas dan bahkan menjangkau sampai ke pelosok-pelosok negeri. Pendayagunaan zakat mulai dilaksanakan pada lima program yaitu kemanusiaan, pendidikan, kesehatan, ekonomi, dan dakwah.

Tata kelola Badan Amil Zakat terus mengalami perbaikan dari waktu ke waktu dan tumbuh. Keterlibatan generasi muda dalam pengelolaan lembaga dapat membangun inovasi pemberdayaan zakat yang dinamis, professional, akuntabel dan syari.

Sebagai upaya dalam meningkatkan pelayanan terhadap masyarakat maka Baznas provinsi Sulawesi Tenggara telah bekerja sama dengan berbagai pihak dan melakukan berbagai inovasi dalam pelayanannya seperti memberikan layanan penjemputan zakat, membuka rekening pembayaran zakat, dan sebagainya. Upaya ini ditujukan untuk memberikan pelayanan yang lebih baik dengan memudahkan masyarakat untuk membayarkan zakatnya, sehingga masyarakat lebih percaya dan selalu membayarkan zakatnya pada Baznas Provinsi Sulawesi Tenggara.

Salah satu factor yang memiliki peran dalam meningkatkan loyalitas masyarakat untuk membayar zakat melalui Baznas adalah

170|| Yusuf, La Ode Anto, Nofrivul, Ulya Atsani bagaimana memberikan service excellence kepada masyarakat untuk memudahkan mereka membayarkan zakatnya (Anggelina, 2010; Kartikasari dan Syafitri, 2018; Hapsari et al., 2012; Thaichon, 2014; Dewi et al., 2019)

Service excellence (Service excellence) menurut Kartikasari dan Syafitri (2018) adalah kepedulian perusahaan dalam memberikan pelayanan terbaik untuk memfasilitasi pemenuhan kebutuhan dan mewujudkan kepuasan pelanggannya, agar mereka selalu loyal terhadap perusahaan tersebut. Loyalitas pelanggan seringkali dikaitkan dengan pembelian berulang, Hasil penelitian Kartikasari dan Syafitri (2018) menyatakan bahwa semakin tinggi kepedulian perusahaan dalam menberikan pelayanan terbaiknya untuk memenuhi kebutuhan pelanggannya maka pelanggan akan meningkatkan pembelian berulangnya kepada perusahaan tersebut, atau dengan kata lain semakin ditingkatkan layanan prima yang diberikan maka pelanggan akan semakin loyal (Alhaqam dan Hamali, 2016); Saputra et al., 2015; Anggelina, 2010; Thaichon et al., 2014; Budiarta dan Fachira, 2017); Saeed et al., 2014; Safnedi, 2019; Dewi et al.2019; Chen dan Liu, 2017; Chou et al., 2014; Jamaluddin dan Ruswanti, 2017; Darmawan, 2018)

Hapsari (2015) juga menjelaskan mengenai service excellence (service excellence) dalam penelitiannya yaitu service excellence berkaitan dengan jasa pelayanan yang dilaksanakan oleh karyawan perusahaan dalam upaya untuk memberikan kepuasan dan menumbuhkan kepercayaan pihak pelanggan (konsumen). Melayani pelanggan dengan baik akan membuat pelanggan merasa diistimewakan, dengan 
memperhatikan kebutuhan pelanggan juga akan sangat membuat pelanggan senang dan dating kembali melakukan pembelian ulang serta merekomendasikan perusahaan kepada orang lain. Namun hasil penelitian Hapsari (2015) menunjukkan bahwa service excellence secara langsung berpengaruh positif tetapi tidak signifikan terhadap loyalitas pelanggan.

Berdasarkan penjelasan tersebutmenunjukkan bahwa pemberian service excellence dapat meningkatkan loyalitas masyarakat dalam membayarkan zakatnya pada Baznas, namun demikian ini perlu dibuktikan karena Hapsari menyatakan bahwa service excellence yang ditujukan untuk mengistimewakan pelanggan dan untuk meningkatkan kepercayaan pelanggan walaupun berpengaruh tetapi tidak signifikan. Oleh karena itu penelitian ini dilakukan untuk menganalisis pengaruh service excellence dalam meningkatkan loyalitas masyarakat dalam membayar zakat pada Baznas Provinsi Sulawesi Tenggara.

Lahirnya Undang-Undang Nomor 38 Tahun 1999 tentang Pengelolaan Zakat merupakan langkah awal pengelolaan zakat yang berlaku secara Nasional. Berdasarkan Surat Keputusan disebutkan tugas dan fungsi BAZNAS (Badan Amil Zakat Nasional) yaitu untuk melakukan penghimpunan dan pendayagunaan zakat. Undang-Undang tersebut menjelaskan bahwa ada dua jenis organisasi pengelola zakat yaitu Badan Amil Zakat (BAZ) yang dibentuk pemerintah dan Lembaga Amil Zakat (LAZ) yang dibentuk oleh masyarakat dan dikukuhkan oleh pemerintah. Adapun BAZ terdiri dari BAZNAS pusat, BAZ Propinsi, BAZ kota, BAZ Kecamatan.
Terbentuknya lembaga zakat yang berbadan hukum dan didukung dengan sosialisasi zakat yang dilakukan oleh lembaga zakat di berbagai media berdampak pada peningkatan kesadaran masyarakat untuk berzakat melalui amil zakat. Sejak tahun 2002 total dana zakat yang berhasil dihimpun BAZNAS dan LAZ mengalami peningkatan pada tiap tahunnya. Selain itu, pendayagunaan zakat juga semakin bertambah luas dan bahkan menjangkau sampai ke pelosok-pelosok negeri. Pendayagunaan zakat mulai dilaksanakan pada lima program yaitu kemanusiaan, pendidikan, kesehatan, ekonomi, dan dakwah.

Tata kelola Badan Amil Zakat terus mengalami perbaikan dari waktu ke waktu dan tumbuh. Keterlibatan generasi muda dalam pengelolaan lembaga dapat membangun inovasi pemberdayaan zakat yang dinamis, professional, akuntabel dan syari.

Sebagai upaya dalam meningkatkan pelayanan terhadap masyarakat maka Baznas provinsi Sulawesi Tenggara telah bekerja sama dengan berbagai pihak dan melakukan berbagai inovasi dalam pelayanannya seperti memberikan layanan penjemputan zakat, membuka rekening pembayaran zakat, dan sebagainya. Upaya ini ditujukan untuk memberikan pelayanan yang lebih baik dengan memudahkan masyarakat untuk membayarkan zakatnya, sehingga masyarakat lebih percaya dan selalu membayarkan zakatnya pada Baznas Provinsi Sulawesi Tenggara.

Salah satu factor yang memiliki peran dalam meningkatkan loyalitas masyarakat untuk membayar zakat melalui Baznas adalah 
bagaimana memberikan service excellence kepada masyarakat untuk memudahkan mereka membayarkan zakatnya (Anggelina, 2010; Kartikasari dan Syafitri, 2018; Hapsari et al., 2012; Thaichon, 2014; Dewi et al., 2019)

Service excellence (Service excellence) menurut Kartikasari dan Syafitri (2018) adalah kepedulian perusahaan dalam memberikan pelayanan terbaik untuk memfasilitasi pemenuhan kebutuhan dan mewujudkan kepuasan pelanggannya, agar mereka selalu loyal terhadap perusahaan tersebut. Loyalitas pelanggan seringkali dikaitkan dengan pembelian berulang, Hasil penelitian Kartikasari dan Syafitri (2018) menyatakan bahwa semakin tinggi kepedulian perusahaan dalam menberikan pelayanan terbaiknya untuk memenuhi kebutuhan pelanggannya maka pelanggan akan meningkatkan pembelian berulangnya kepada perusahaan tersebut, atau dengan kata lain semakin ditingkatkan layanan prima yang diberikan maka pelanggan akan semakin loyal (Alhaqam dan Hamali, 2016); Saputra et al., 2015; Anggelina, 2010; Thaichon et al., 2014; Budiarta dan Fachira, 2017); Saeed et al., 2014; Safnedi, 2019; Dewi et al.2019; Chen dan Liu, 2017; Chou et al., 2014; Jamaluddin dan Ruswanti, 2017; Darmawan, 2018)

Hapsari (2015) juga menjelaskan mengenai service excellence (service excellence) dalam penelitiannya yaitu service excellence berkaitan dengan jasa pelayanan yang dilaksanakan oleh karyawan perusahaan dalam upaya untuk memberikan kepuasan dan menumbuhkan kepercayaan pihak pelanggan (konsumen). Melayani pelanggan dengan baik akan membuat pelanggan merasa diistimewakan, dengan memperhatikan kebutuhan pelanggan juga

172 | Yusuf, La Ode Anto, Nofrivul, Ulya Atsani akan sangat membuat pelanggan senang dan dating kembali melakukan pembelian ulang serta merekomendasikan perusahaan kepada orang lain. Namun hasil penelitian Hapsari (2015) menunjukkan bahwa service excellence secara langsung berpengaruh positif tetapi tidak signifikan terhadap loyalitas pelanggan.

Berdasarkan penjelasan tersebutmenunjukkan bahwa pemberian service excellence dapat meningkatkan loyalitas masyarakat dalam membayarkan zakatnya pada Baznas, namun demikian ini perlu dibuktikan karena Hapsari menyatakan bahwa service excellence yang ditujukan untuk mengistimewakan pelanggan dan untuk meningkatkan kepercayaan pelanggan walaupun berpengaruh tetapi tidak signifikan. Oleh karena itu penelitian ini dilakukan untuk menganalisis pengaruh service excellence dalam meningkatkan loyalitas masyarakat dalam membayar zakat pada Baznas Provinsi Sulawesi Tenggara.

Lahirnya Undang-Undang Nomor 38 Tahun 1999 tentang Pengelolaan Zakat merupakan langkah awal pengelolaan zakat yang berlaku secara Nasional. Berdasarkan Surat Keputusan disebutkan tugas dan fungsi BAZNAS (Badan Amil Zakat Nasional) yaitu untuk melakukan penghimpunan dan pendayagunaan zakat. Undang-Undang tersebut menjelaskan bahwa ada dua jenis organisasi pengelola zakat yaitu Badan Amil Zakat (BAZ) yang dibentuk pemerintah dan Lembaga Amil Zakat(LAZ) yang dibentuk oleh masyarakat dan dikukuhkan oleh pemerintah. Adapun BAZ terdiri dari BAZNAS pusat, BAZ Propinsi, BAZ kota, BAZ Kecamatan.

Terbentuknya lembaga zakat yang berbadan hukum dan didukung dengan sosialisasi zakat 
yang dilakukan oleh lembaga zakat di berbagai media berdampak pada peningkatan kesadaran masyarakat untuk berzakat melalui amil zakat. Sejak tahun 2002 total dana zakat yang berhasil dihimpun BAZNAS dan LAZ mengalami peningkatan pada tiap tahunnya. Selain itu, pendayagunaan zakat juga semakin bertambah luas dan bahkan menjangkau sampai ke pelosok-pelosok negeri. Pendayagunaan zakat mulai dilaksanakan pada lima program yaitu kemanusiaan, pendidikan, kesehatan, ekonomi, dan dakwah.

Tata kelola Badan Amil Zakat terus mengalami perbaikan dari waktu ke waktu dan tumbuh. Keterlibatan generasi muda dalam pengelolaan lembaga dapat membangun inovasi pemberdayaan zakat yang dinamis, professional, akuntabel dan syari.

Sebagai upaya dalam meningkatkan pelayanan terhadap masyarakat maka Baznas provinsi Sulawesi Tenggara telah bekerja sama dengan berbagai pihak dan melakukan berbagai inovasi dalam pelayanannya seperti memberikan layanan penjemputan zakat, membuka rekening pembayaran zakat, dan sebagainya. Upaya ini ditujukan untuk memberikan pelayanan yang lebih baik dengan memudahkan masyarakat untuk membayarkan zakatnya, sehingga masyarakat lebih percaya dan selalu membayarkan zakatnya pada Baznas Provinsi Sulawesi Tenggara.

Salah satu factor yang memiliki peran dalam meningkatkan loyalitas masyarakat untuk membayar zakat melalui Baznas adalah bagaimana memberikan service excellence kepada masyarakat untuk memudahkan mereka membayarkan zakatnya (Anggelina, 2010;
Kartikasari dan Syafitri, 2018; Hapsari et al., 2012; Thaichon, 2014; Dewi et al., 2019)

Service excellence (Service excellence) menurut Kartikasari dan Syafitri (2018) adalah kepedulian perusahaan dalam memberikan pelayanan terbaik untuk memfasilitasi pemenuhan kebutuhan dan mewujudkan kepuasan pelanggannya, agar mereka selalu loyal terhadap perusahaan tersebut. Loyalitas pelanggan seringkali dikaitkan dengan pembelian berulang, Hasil penelitian Kartikasari dan Syafitri (2018) menyatakan bahwa semakin tinggi kepedulian perusahaan dalam menberikan pelayanan terbaiknya untuk memenuhi kebutuhan pelanggannya maka pelanggan akan meningkatkan pembelian berulangnya kepada perusahaan tersebut, atau dengan kata lain semakin ditingkatkan layanan prima yang diberikan maka pelanggan akan semakin loyal (Alhaqam dan Hamali, 2016); Saputra et al., 2015; Anggelina, 2010; Thaichon et al., 2014; Budiarta dan Fachira, 2017); Saeed et al., 2014; Safnedi, 2019; Dewi et al.2019; Chen dan Liu, 2017; Chou et al., 2014; Jamaluddin dan Ruswanti, 2017; Darmawan, 2018)

Hapsari (2015) juga menjelaskan mengenai service excellence (service excellence) dalam penelitiannya yaitu service excellence berkaitan dengan jasa pelayanan yang dilaksanakan oleh karyawan perusahaan dalam upaya untuk memberikan kepuasan dan menumbuhkan kepercayaan pihak pelanggan (konsumen). Melayani pelanggan dengan baik akan membuat pelanggan merasa diistimewakan, dengan memperhatikan kebutuhan pelanggan juga akan sangat membuat pelanggan senang dan 
dating kembali melakukan pembelian ulang serta merekomendasikan perusahaan kepada orang lain. Namun hasil penelitian Hapsari (2015) menunjukkan bahwa service excellence secara langsung berpengaruh positif tetapi tidak signifikan terhadap loyalitas pelanggan.

Berdasarkan penjelasan tersebut menunjukkan bahwa pemberian service excellence dapat meningkatkan loyalitas masyarakat dalam membayarkan zakatnya pada Baznas, namun demikian ini perlu dibuktikan karena Hapsari menyatakan bahwa service excellenceyang ditujukan untuk mengistimewakan pelanggan dan untuk meningkatkan kepercayaan pelanggan walaupun berpengaruh tetapi tidak signifikan. Oleh karena itu penelitian ini dilakukan untuk menganalisis pengaruh service excellence dalam meningkatkan loyalitas masyarakat dalam membayar zakat pada Baznas Provinsi Sulawesi Tenggara.

\section{Kerangka Konseptual}

\section{Loyalitas}

Pada saat persaingan yang sangat ketat dan meningkatnya harapan pelanggan maka sangat penting bagi perusahaan untuk lebih fokus mempertahankan pelanggan karena biaya yang harus dikeluarkan untuk menarik pelanggan baru lebih besar daripada biaya untuk mempertahankan pelanggan yang sudah ada (Zeithaml et al., 2009:176). Pada umumnya perusahan sangat tergantung pada pembelian berulang dari pelanggan yang loyal dan menjadikan loyalitas pelanggan sebagai salah satu tujuan strategis dari perusahaan. Keuntungan yang dihasilkan dengan memiliki basis pelanggan setia bukan hanya efek

$174 \mid$ Yusuf, La Ode Anto, Nofrivul, Ulya Atsani pendapatan yang besar tetapi juga karena biaya untuk mempertahankan pelanggan relatif lebih kecil daripada menarik pelanggan baru.

Indikator yang dapat digunakan untuk mengukur loyalitas pelanggan menurut Bowen dan Chen (2001) yaitu: Pembelian berulang, Menceritakan kepada orang lain, Memberikan rekomendasi kepada orang lain, Tidak terpengaruh tawaran badan atau lembaga zakat lain, dan Menyampaikan complain kepada Baznas.

Loyalitas pelanggan dalam penelitian Kartikasari dan Syafitri (2018) sangat kuat dipengaruhi oleh service excellence dari perusahaan, dimana menurut Kartikasari dan Syafitri (2018) layanan prima (Service excellence) adalah kepedulian perusahaan dalam memberikan pelayanan terbaik untuk memfasilitasi pemenuhan kebutuhan dan mewujudkan kepuasan pelanggannya, agar mereka selalu loyal terhadap perusahaan tersebut. Temuan penelitian Kartikasari dan Syafitri (2018) ini diperkuat oleh beberapa penelitian terdahulu yaitu penelitian Alhaqam dan Hamali (2016); Saputra et al. (2015); Anggelina (2010); Thaichon et al. (2014); Budiarta dan Fachira (2017); Saeed et al. (2014); Safnedi (2019); Dewi et al. (2019); Chen dan Liu (2017); Chou et al (2014); Jamaluddin dan Ruswanti (2017); Darmawan (2018).

\section{Service Excellence}

Service excellence adalah kepedulian terhadap pelanggan dengan memberikan layanan terbaik untuk memfasilitasi pemenuhan kebutuhan dan mewujudkan kepuasannya, agar mereka selalu loyal kepada organisasi / perusahaan (Barata, 2011). 


\section{Dimensi Service Excellence}

1. Attitude, perilaku atau perangai karyawan yang harus ditonjolkan ketika menghadapi pelanggan. Adapun indicator sikap yaitu sikap yang baik dan sikap yang menarik

2. Attention, kepedulian penuh terhadap pelanggan baik yang berkaitan dengan perhatian akan kebutuhan dan keinginan pelanggan maupun pemahaman atas saran dan kritikan. Indikator perhatian yaitu Perhatian akan kebutuhan dan keinginan pelanggan dan pemahaman atas kritik dan saran pelanggan

3. Action, berbagai kegiatan nyata yang harus dilakukan dalam memberikan layanan kepada pelanggan. Indikator tindakan dalam penelitian ini mengacu pada Barata (2011), yaitu: mencatat kebutuhan pelanggan, mewujudkan kebutuhan pelanggan
4. Ability, pengetahuan dan keterampilan tertentu yang mutlak diperlukan untuk menunjang program layanan prima. Indikator kemampuan yaitu pengetahuan yang dimiliki karyawan dalam menyampaikan layanan, keterampilan yang dimiliki karyawan dalam menyampaikan layanan.

5. Appereance, penampilan karyawan baik bersifat fisik saja maupun non-fisik, yang mampu merefleksikan kepercayaan diri dan kredibilitas dari pihak lain. Indikator penampilan yaitu penampilan fisik, penampilan non fisik

6. Accountability, sikap keberpihakan kepada pelanggan sebagai wujud kepedulian untuk menghindarkan atau meminimalkan kerugian atau ketidakpuasan pelanggan. Indikator tanggungjawab yaitu melayani pelanggan saat tidak bertugas.

Gambar 1.

Kerangka Konsep Penelitian

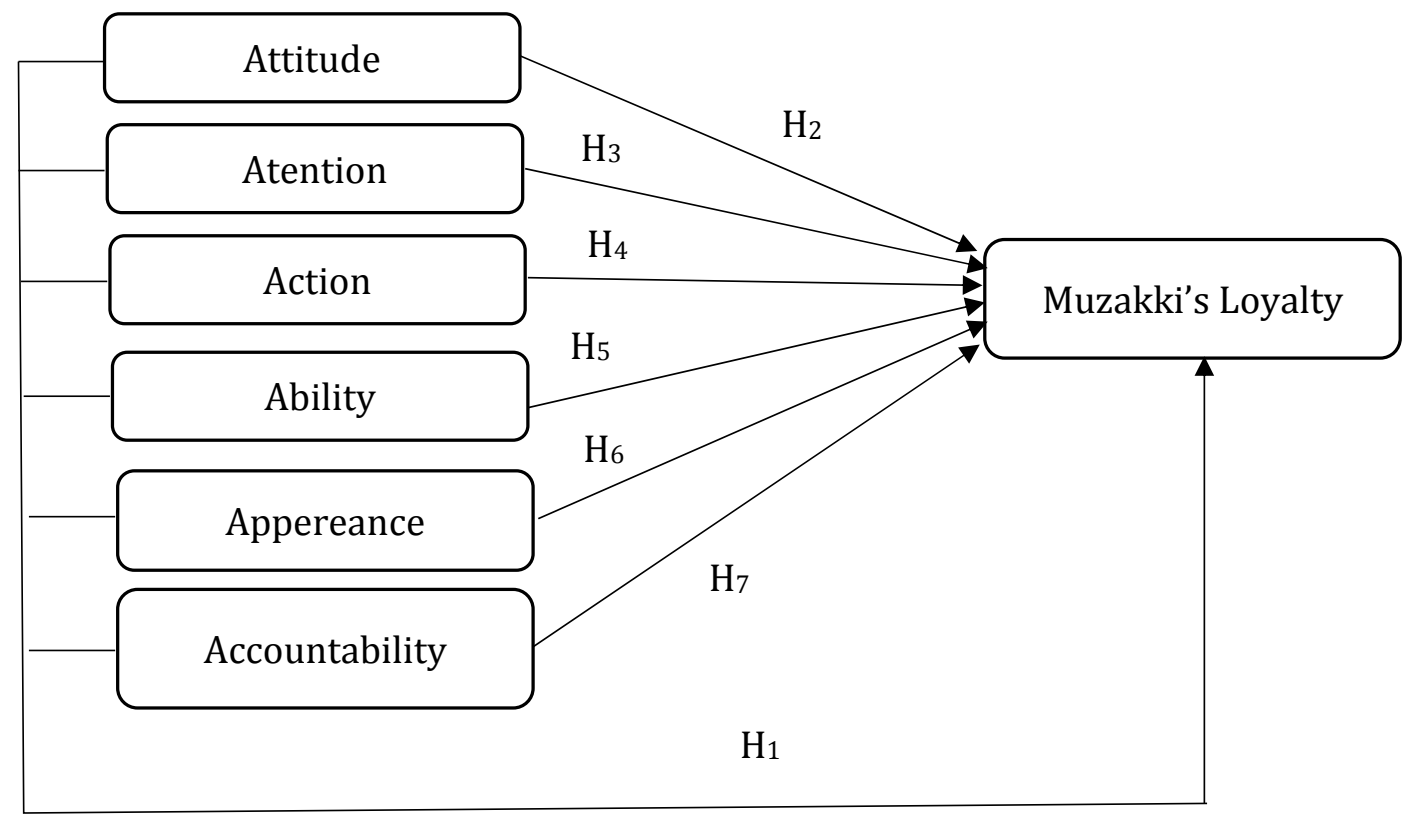




\section{METODE PENELITIAN}

Rancangan penelitian ini menggunakan pendekatan explanatory research dengan maksud untuk memberikan penjelasan hubungan kausal antar variabel melalui pengujian hipotesis atau bertujuan untuk memperoleh pengujian yang tepat dalam menarik kesimpulan yang bersifat kausalitas (sebab-akibat) antara variabel (Kuncoro, 2003). Besarnya jumlah populasi tidak dapat diketahui secara pasti karena tidak terdapat data riil jumlah masyarakat pembayar zakat yang ada di Sulawesi Tenggara. Berdasarkan hal tersebut maka penentuan jumlah sampel dilakukan dengan mengacu pada Ferdinand (2006; 38) yang menyatakan bahwa untuk menentukan besaran sampel dapat dilakukan dengan pendekatan 5 - 10 kali jumlah indicator variable bebas. Jumlah indicator dari keseluruhan variable bebas adalah 12 , oleh karena itu maka sampel yang digunakan adalah $10 \times 12=120$ responden. Analisis data dalam penelitian ini menggunakan regresi linier berganda.

\section{PEMBAHASAN DAN HASIL}

\section{Pengujian Hipotesis Secara Simultan}

Pengujian hipotesis secara simultan dapat diuji berdasarkan nilai $\mathrm{F}$ hitung atau probabilitas $\left(\mathrm{F}_{\mathrm{Sig}}\right.$ ).

\section{1. $H_{1}$ : Attitude, Attention, Action, Ability, Appereance, dan Accountability secara simultan berpengaruh signifikan terhadap loyalitas}

Hasil pengujian menunjukkan bahwa nilai F hitung yang dihasilkan adalah sebesar 134.087 dengan tingkat probabilitas (sig.) sebesar 0,000.
Tingkat probabilitas (Sig.) yang dihasilkan tersebut lebih kecil daripada level of significant $(\alpha)$ yang ditetapkan yaitu sebesar 0,05 . Penelitian yang menyatakan Attitude, Attention, Action, Ability, Appereance, dan Accountability secara simultan berpengaruh positif dan signifikan terhadap Loyalitas masyarakat pembayar zakat dapat diterima.

Berdasarkan hal tersebut maka dapat dijelaskan bahwa semakin baik Attitude, Attention, Action, Ability, Appereance, dan Accountability akan meningkatkan Loyalitas Muzakki.

\section{Pengujian Hipotesis Secara Parsial}

Pengujian hipotesis secara parsial dalam penelitian didasarkan pada hasil uji t statistik yang digunakan untuk menguji tingkat signifikansi secara parsial antara variabel independen (X) dan dependen (Y). Uji t ini digunakan untuk mengetahui ketepatan prediksi dari koefisien regresi yang diperoleh, semakin besar nilai uji t dan semakin kecil nilai signifikansi, berarti ketepatan prediksi yang dispesifikasikan dalam model regresi semakin akurat. Hasil pengujian hipotesis secara parsial dijelaskan sebagai berikut:

\section{1. $\mathrm{H}_{2}$ : Attitude Berpengaruh Positif dan Signifikan Terhadap Loyalitas}

Hasil pengujian menunjukkan bahwa nilai t hitung untuk variabel attitude adalah sebesar 2,123 dengan koefisien regresinya sebesar 0,117 dan nilai probabilitas (sig.) sebesar 0,036. Nilai probabilitas yang dihasilkan tersebut lebih kecil daripada nilai level of significant $(\alpha)$ 
yang ditetapkan yaitu sebesar 0,05. Hasil ini menunjukkan bahwa hipotesis yang menyatakan variabel "attitude berpengaruh positif dan signifikan terhadap loyalitas", dapat diterima. Berdasarkan hal tersebut maka temuan ini dapat dijelaskan bahwa semakin baik sikap petugas Baznas dalam melayani masyarakat pembayar zakat maka loyalitas masyarakat pembayar zakat akan semakin meningkat. Hasil penelitian ini mendukung temuan penelitian

\section{2. $H_{3}$ : Attention Berpengaruh Positif dan Signifikan Terhadap Loyalitas}

Hasil pengujian menunjukkan bahwa nilai $t$ hitung untuk variabel attention adalah sebesar 3,873 dengan koefisien regresinya sebesar 0,246 dan nilai probabilitas (sig.) sebesar 0,000. Nilai probabilitas yang dihasilkan tersebut lebih kecil daripada nilai level of significant $(\alpha)$ yang ditetapkan yaitu sebesar 0,05. Hasil ini menunjukkan bahwa hipotesis yang menyatakan variabel "attention berpengaruh positif dan signifikan terhadap loyalitas", dapat diterima. Berdasarkan hal tersebut maka temuan ini dapat dijelaskan bahwa semakin tinggi perhatian petugas Baznas dalam melayani masyarakat pembayar zakat maka loyalitas masyarakat pembayar zakat juga akan semakin meningkat

\section{3. $H_{4}$ : Action Berpengaruh Positif dan Signifikan Terhadap Loyalitas}

Hasil pengujian menunjukkan bahwa nilai t hitung untuk variabel action adalah sebesar 2,016 dengan koefisien regresinya sebesar 0,130 dan nilai probabilitas (sig.) sebesar 0,046. Nilai probabilitas yang dihasilkan tersebut lebih kecil daripada nilai level of significant $(\alpha)$ yang ditetapkan yaitu sebesar 0,05. Hasil ini menunjukkan bahwa hipotesis yang menyatakan variabel "action berpengaruh positif dan signifikan terhadap loyalitas", dapat diterima. Berdasarkan hal tersebut maka temuan ini dapat dijelaskan bahwa semakin tanggap tindakan petugas Baznas dalam melayani masyarakat pembayar zakat maka loyalitas masyarakat pembayar zakat juga akan semakin meningkat

\section{4. $H_{5}$ : Ability Berpengaruh Positif dan Signifikan Terhadap Loyalitas}

Hasil pengujian menunjukkan bahwa nilai t hitung untuk variabel ability adalah sebesar 3,458 dengan koefisien regresinya sebesar 0,180 dan nilai probabilitas (sig.) sebesar 0,001. Nilai probabilitas yang dihasilkan tersebut lebih kecil daripada nilai level of significant $(\alpha)$ yang ditetapkan yaitu sebesar 0,05. Hasil ini menunjukkan bahwa hipotesis yang menyatakan variabel "ability berpengaruh positif dan signifikan terhadap loyalitas", dapat diterima. Berdasarkan hal tersebut maka temuan ini dapat dijelaskan bahwa semakin baik kemampuan petugas Baznas dalam melayani masyarakat pembayar zakat maka loyalitas masyarakat pembayar zakat juga akan semakin meningkat.

\section{5. $H_{6}:$ Appereance Berpengaruh Positif dan Signifikan Terhadap Loyalitas}

Hasil pengujian menunjukkan bahwa nilai $\mathrm{t}$ hitung untuk variabel appereance adalah sebesar 4,647 dengan koefisien regresinya sebesar 0,249 dan nilai probabilitas (sig.) sebesar 0,000. Nilai probabilitas yang dihasilkan tersebut 
lebih kecil daripada nilai level of significant $(\alpha)$ yang ditetapkan yaitu sebesar 0,05. Hasil ini menunjukkan bahwa hipotesis yang menyatakan variabel "appereance berpengaruh positif dan signifikan terhadap loyalitas", dapat diterima. Berdasarkan hal tersebut maka temuan ini dapat dijelaskan bahwa semakin baik penampilan petugas Baznas dalam melayani masyarakat pembayar zakat maka loyalitas masyarakat pembayar zakat juga akan semakin meningkat

\section{6. $H_{7}$ : Accountability Berpengaruh Positif dan Signifikan Terhadap Loyalitas}

Hasil pengujian menunjukkan bahwa nilai t hitung untuk variabel accountability adalah sebesar 2,350 dengan koefisien regresinya sebesar 0,152 dan nilai probabilitas (sig.) sebesar 0,021 . Nilai probabilitas yang dihasilkan tersebut lebih kecil daripada nilai level of significant $(\alpha)$ yang ditetapkan yaitu sebesar 0,05. Hasil ini menunjukkan bahwa hipotesis yang menyatakan variabel "accountability berpengaruh positif dan signifikan terhadap loyalitas", dapat diterima. Berdasarkan hal tersebut maka temuan ini dapat dijelaskan bahwa semakin tinggi tanggungjawab petugas Baznas dalam melayani masyarakat pembayar zakat maka loyalitas masyarakat pembayar zakat juga akan semakin meningkat.

Temuan penelitian ini menunjukkan bahwa pelayanan prima merupkan factor penting dalam meningkatkan loyalitas muzakki. Hasil ini sejalan dengan temuan Anggelina (2010) yang menunjukkan bahwa secara simultan seluruh dimensi service excellence berpengaruh signifikan terhadap loyalitas pelanggan. Temuan penelitian ini sejalan dengan pendapat Barata
(2003: 27) yang menyatakan bahwa, "pelayanan prima adalah kepedulian terhadap pelanggan dengan memberikan layanan terbaik untuk memfasilitasi pemenuhan kebutuhan dan mewujudkan kepuasannya, agar mereka selalu loyal kepada perusahaan.

Temuan penelitian ini diperkuat oleh Rahmayanti (2010) yang menyatakan bahwa kesetiaan pelanggan tidak dapat dibeli dan dipaksakan, kesetiaan hanya dapat diperoleh dengan melalui proses memuaskan kebutuhan dan keinginan pelanggan dari waktu ke waktu dengan memberikan pelayanan prima. Pelayanan prima merupakan factor penting yang harus dijaga oleh perusahaan karena berpengaruh terhadap kelangsungan hidup perusahaan (Daryanto dan setyobudi, 2014).

\section{PENUTUP}

\section{Kesimpulan}

Berdasarkan hasil analisis data dan pembahasan diatas, maka dapat ditarik kesimpulan bahwa service excellence merupakan factor penting yang perlu dilakukan dan ditingkatkan oleh Baznas Wilayah Provinsi Sulawesi Tenggara karena terbukti seluruh dimensi yang ada pada service excellence berperan penting dalam meningkatkan loyalitas Muzakki. Hasil penelitian ini konsisten dengan kajian literature dan empiris sebelumnya dimana service excellence yang terdiri dari Attitude, Attention, Action, Ability, Appereance, and Accountability, jika di laksanakan secara baik maka Muzakki akan membayarkan zakatnya 
kembali pada Baznas serta merekomendasikan Baznas kepada teman dan keluarganya.

\section{Saran}

Temuan penelitian ini menunjukkan bahwa dimensi Appereance dan Attention merupakan dimensi yang paling kuat perannya dalam meningkatkan loyalitas Muzakki, oleh karena itu tentunya ini sangat penting bagi pihak Baznas untuk menjadikannya sebagai icon pemasarannya.

Penelitian ini telah dilakukan dengan usaha yang optimal namun tentunya hasil yang diharapkan untuk mendekati arah kesempurnaan masih belum bisa diwujudkan, penelitian ini masih memiliki keterbatasan yaitu pengumpulan data dilakukan pada kantor Baznas provinsi Sulawesi Tenggara sehingga responden yang terjaring umumnya adalah orang-orang yang berdomisili di Kota Kendari sehingga penelitian ini belum mampu menjelaskan kondisi riil provinsi Sulawesi Tenggara.

Harapan peneliti untuk peneliti kedepannya bisa mengembangkan penelitian ini dengan menghubungkan service excellence terhadap kepuasan pembayar zakat dengan responden yang diambil di setiap kantor Baznas di seluruh kabupaten kota yang ada di Provinsi Sulawesi Tenggara.

\section{DAFTAR KEPUSTAKAAN}

Al-Haqam, Rizki Faiz dan Hamali, Arif Yusuf (2016). The Influence of Service Quality Toward Customer Loyalty: A Case Study at Alfamart Abdurahman Saleh Bandung. Binus Business Review, 7(2), August 2016, 203-212
Asadpoor, Saeedeh dan Abolfazli, Abolfazl (2017). Effect of Electronic Service Quality on Customer Satisfaction and Loyalty Saderat Bank's Customers. International Journal of Scientific Study | July 2017 | Vol 5 | Issue 4

Asih, Nyoman Suparmanti (2016). Pengaruh Service excellence (Service Excellence) Terhadap Kepuasan Pelanggan Salon Agata Singaraja. Jurnal Program Studi Pendidikan Ekonomi (JPPE) Volume: 7 Nomor: 2 Tahun: 2016

Barata, Atep Adya. (2011). Dasar-Dasar Service excellence. Jakarta: PT.Elex Media Komputindo.

Bowen, John T. and Chen, Shiang-Lih. 2001. The Relationship Between Customer Loyalty and Customer Satisfaction, International Journal of Contemporary Hospitality Management, Vol. 13 Iss: 5 pp. 213 - 217

Daryanto, \& Setyobudi, I. (2014). Konsumen dan service excellence. Yogyakarta: Gava Media

Day, G. S., 1969. A two-dimensional concept of brand loyalty. Journal of Advertising Research, 9, pp. 29-35.

Dick, Alan. S., Basu, Kunal., 1994. Customer Loyalty : Toward an Integrated Conceptual Framework. Journal of Academy of Marketing Science 22, (2) pp. 99-113.

Gillani, Aamina., Rab Nawaz Lodhi1 S.M. Irfan, Zahid Mehmood (2016). Examining The Relationship Between Service Excellence and Customer Delight: Mediating Role of Customer Satisfaction. Sci.Int.(Lahore),28 (4), 3983-3988, 2016. 
Hapsari, Annisa Mirandha., Srikandi Kumadji, Yusri Abdillah (2015). Pengaruh Excellent Service Terhadap Kepuasan Pelanggan Serta Dampaknya Pada Loyalitas Pelanggan (Survei pada Pelanggan Pizza Hut Malang Town Square). Jurnal Administrasi Bisnis (JAB)| Vol. 1 No. 2 Januari 2015

Kartikasari, Dwi. dan Syafitri, Dea Arista ( 2018). Efektivitas Service excellence (Service Excellence) Terhadap Kepuasan Pelanggan Yang Berdampak Pada Loyalitas Pelanggan Pada Toko Obat Dewi Farma. Politeknik Negeri Batam.

Lupiyoadi, Rambat. (2011). Manajemen Pemasaran Jasa Teori dan Praktek. Edisi Pertama, Jakarta: Salemba Empat.

Rahmayanty, Nina. 2010. Manajemen Service excellence, Edisi Pertama. Yogyakarta: Graha Ilmu.

Thaichon, Paramaporn., Antonio Lobo and Ann Mitsis (2014). Achieving customer loyalty through service excellence in internet industry. International Journal of Quality and Service Sciences Vol. 6 No. 4, 2014 pp. 274-289
Rangkuti, Fredy, (2010), Riset Pemasaran. Cetakan Kelima. Jakarta: PT. Gramedia Pustaka Utama. Ruslan, Rosady. (2005). Manajemen Public Relations dan Media Komunikasi, konsepsi, dan aplikasi, edisi revisi, Jakarta, PT. Raja Grafindo Persada.

Tjiptono, Fandy. (2012). Pemasaran Stategik. Yogyakarta: CV. Andi Offset.

Yusuf, Moeljadi, Fatchur Rohman, Mintarti Rahayu (2015). Customer Income as the Moderator on the Relation of Customer Satisfaction, Loyalty and Switching Intention (Study Case through Telkomsel Customers at Makassar City). International Journal of Business and Management Invention ISSN (Online): 2319 - 8028, ISSN (Print): 2319 - 801X www.ijbmi. org || Volume 4 Issue 2|| February. 2015 || PP.16-24

Zeithaml, Valarie A., Bitner, Mary J., and Gremler, Dwayne D., 2009. Services Marketing, Fifth Edition. McGraw-Hill. 